\title{
NARRATIVA AUTOBIOGRÁFICA E FORMAÇÃO DOCENTE EM GEOGRAFIA reconstruindo percursos formativos a partir da narrativa da experiência
}

\author{
Jessica da Silva Rodrigues Cecim ${ }^{1}$ \\ Rafael Straforini ${ }^{2}$
}

\begin{abstract}
Resumo: Este texto tem por objetivo apresentar narrativa autobiográfica enquanto recurso metodológico de pesquisa e de constituição da identidade docente em Geografia. Trata-se de uma pesquisa autobiográfica realizada em 2016 no âmbito do Pibid-Geografia, que se desdobrou no trabalho de conclusão de curso, no qual o objetivo foi compreender como se configuram as relações existentes entre uma aluna bolsista de Iniciação à Docência (ID) e o Professor Supervisor dentro do contexto das atividades do Programa Institucional de Bolsas de Iniciação à Docência (Pibid) do subprojeto Geografia - Unicamp; considerando que nesta relação ambos os sujeitos exerceram influências na formação docente um do outro. $\mathrm{O}$ enfoque neste texto é o de analisar como se realizou a opção metodológica pela narrativa autobiográfica e em como esta escolha influenciou a pesquisadora em seu percurso formativo, bem como para a autorreflexão no processo de produção de sua identidade docente.
\end{abstract}

Palavras-chave: Narrativa Autobiográfica. Memória. Formação Docente. Pibid.

\section{AUTOBIOGRAPHIC NARRATIVE AND TEACHERS' TRAINING IN GEOGRAPHY reconstructing formative paths from the narrative of experience}

\begin{abstract}
This text aims to present the autobiographic narrative as a methodological resource for research and teachers' identity construction in Geography. It is constituted of an autobiographical research done in 2016 in the scope of Pibid - Geography that unfolded as the final paper, which aimed to understand how the existing relations are established between a scholar of teaching initiation and the supervisor professor within the context of the activities of the Institutional Program of Scholarship in Teaching Initiation (Pibid) of the subproject Geography - Unicamp; considering that in this relation both individuals influenced each other's teachers' training. The focus in this text is to analyze how the methodological choices took place through the autobiographic narrative and how this choice influenced the scholar in her training path as well as for the self-reflection in the process of creating her teacher identity.
\end{abstract}

Keywords: Autobiographic Narrative. Memory. Teachers' training. Pibid.

\footnotetext{
1 Mestranda no Programa de Pós-Graduação em Geografia da Universidade Estadual de Campinas (Unicamp). E-mail: jcecim@gmail.com

2 Doutor em Geografia pela UFRJ (2007), mestre em Educação Aplicada às Geociências pela UNICAMP (2001) e graduado (bacharelado e licenciatura) em Geografia pela UNESP/Rio Claro (1997). Docente do Departamento de Geografia do Instituto de Geociências da Universidade Estadual de Campinas Unicamp, atuando como docente nos cursos de Licenciatura em Geografia e Pós-Graduação em Geografia. E-mail: rafaels trafo@yahoo.com.br
} 


\section{REVISTA ELETRÔNICA \\ DA GRADUAÇÃO/PÓS-GRADUAÇÃOO EM EDUCAÇÃO}

UFG/REJ

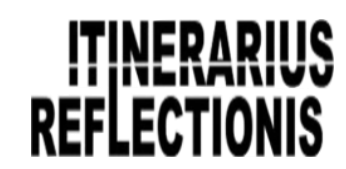

ISS N. 1807-9342

Volume 14, N. 2, 2018

\section{INTRODUÇÃO}

"Talvez não sejamos outra coisa que um modo particular de contarmos o que somos. E para isso, para contarmos o que somos, talvez não tenhamos outra possibilidade que recorrer de novo às ruínas da nossa biblioteca para intentar lá pegar as palavras que nos nomeiam, que nos dizem" (LARROSA, 1995, p. 192).

Este artigo tem o intuito de discutir as contribuições da pesquisa narrativa no desenvolvimento de trabalhos acadêmicos, sobretudo, naqueles que se preocupam em abordar a formação docente. Como pano de fundo para as nossas discussões nos utilizaremos de uma pesquisa de conclusão de curso, que se utilizou das experiências e vivências produzidas no âmbito das atividades do Pibid-Geografia da Unicamp, em que a narrativa autobiográfica foi apropriada enquanto recurso metodológico pela pesquisadora na condição de dupla função que ocupou: a de pesquisadora e a de pesquisada enquanto ex-bolsista de Iniciação à Docência. O texto será ora apresentado na primeira pessoa do plural, quando os movimentos tratarem daquilo que foi e é uma construção coletiva, e ora na primeira pessoa do singular, quando os movimentos narrados se referirem à fala e ao pensamento da própria pesquisadora. Não obstante, essa escolha de não fixar na textualidade "o" ou "os" seus sujeitos da fala, ainda que que possa soar uma cacofonia ao leitor, nos é uma ação deliberadamente metodológica e apoiada nos trabalhos de Prado; Serodio; Proença et al (2015) e Costa; Evangelista; Prado (2017).

A escrita de si surgiu ao longo do desenvolvimento da pesquisa em forma de descoberta para a própria pesquisadora e ao seu orientador, que na ocasião era o coordenador do subprojeto Geografia, pois o objeto de pesquisa já estava definido, bem como os seus objetivos. A metodologia, no entanto, foi se revelando aos poucos, percorrendo por caminhos que não foram confortáveis em um primeiro momento, visto que carregavam em muitas inquietudes no que diz respeito à autobiografia.

Ao nos depararmos com a produção bibliográfica referente às narrativas e à narrativa autobiográfica deslocamo-nos em direção a uma perspectiva que legitima a experiência como produção de conhecimento. Deste modo, nos valemos dos estudos de Rabelo (2011, p. 177), para quem "as narrações de nós mesmos nos ajudam a construir nosso significado, tanto para cada um, quanto para os outros na sociedade”. 


\section{REVISTA ELETRÔNICA \\ DA GRADUAÇÃO/PÓS-GRADUAÇÃO EM EDUCAÇÃO}

UFG/REJ

\section{ITINERPARUIS \\ REFLECTIONIS}

ISSN. 1807-9342

Volume 14, N. 2, 2018

Sob os pilares da narrativa, da autobiografia e da memória passamos instigar e refletir sobre a própria formação docente em Geografia. Com esse intuito, a proposta foi trilhar por caminhos que extrapolavam o ambiente do Pibid Geografia - Unicamp, buscando o entranhamento nas memórias do próprio percurso formativo de maneira mais ampla, percorrendo o momento da escolha do curso de bacharel em Geografia como o foco da formação, os espaçostempo ${ }^{3}$ de socialização universitária, o pensar e querer ser professora e, a consequente mudança do foco da formação, as escolas de ensino básico com as quais se teve contato, o grupo de pesquisa do qual se faz parte até as relações estabelecidas durante todos esses processos. "E não podemos deixar de mencionar a potencialidade da narrativa enquanto procedimento teórico-metodológico, que favorece a explicitação do vivido como também possibilita a teorização do vivido, transformando-o em conhecimento acadêmico" (RODRIGUES e PRADO, 2015, p. 101).

Apresentamos neste trabalho, portanto, como a narrativa autobiográfica permitiu que uma licencianda em Geografia desse significado às experiências com as quais teve contato, fazendo uma leitura de si mesma que não carregava em si o intuito de trazer verdades acerca da formação docente no cenário em que se situava, mas como um exercício de reflexão sobre as possibilidades de um percurso formativo de uma pibidiana no contexto em que estava inserida.

\section{NARRATIVAS E MEMÓRIA: o que conto e o que não conto}

No texto "O Narrador" de Walter Benjamin (1987), ao analisar a obra de Nikolai Leskov, o autor discorre sobre a questão da narrativa, suas finalidades, formato e acerca do declínio da arte narrativa na modernidade. Este texto de Benjamin, é intensamente trabalhado na atualidade em diversas pesquisas de cunho narrativo (EWALD, 2008, SILVA, 2014, RODRIGUES e PRADO, 2015, CARVALHO e PRADO, 2017;

\footnotetext{
${ }^{3}$ O termo é constantemente utilizado nos textos de Nilda Alves, para quem "Esse modo de escrever se mostrou necessário para tanto buscar quanto superar a dicotomização herdada do período no qual se "construiu" a ciência moderna". Nesse sentido, na neologia em questão podemos nos utilizar tanto de "espaçotempo", quanto "tempoespaço", de modo que a ordem das palavras não altera seu significado. ALVES, Nilda. Cultura e cotidiano escolar. Revista Brasileira de Educação, No 23, Maio/Jun/Jul/Ago, 2003.
} 


\section{REVISTA ELETRÔNICA \\ DA GRADUAÇÃO/PÓS-GRADUAÇÃOO EM EDUCAÇÃO}

UFG/REJ

\section{ITWERPMU \\ REFLECTIONIS}

ISS N. 1807-9342

Volume 14, N. 2, 2018

PRADO, et al 2015), por inspirar ou estimular o autor a se assumir como narrador e personagem na escrita, trazendo suas experiências para a textualidade.

Para Benjamin (1987), a narrativa não carrega em si a preocupação de informar, sendo ela própria, uma forma artesanal de comunicação. Neste sentido, a narrativa se distingue do relatório que apresenta este cunho informativo, pois, num movimento contrário "ela mergulha a coisa na vida do narrador para em seguida retirá-la dele. Assim se imprime na narrativa a marca do narrador, como a mão do oleiro na argila do vaso" (p. 204).

Assim, a narrativa não é algo que se faça só. $\mathrm{O}$ autor acima ainda a compara ao romance, afirmando que este tem sua origem no indivíduo isolado, sendo o surgimento do romance no início do período moderno a marca indício da evolução que culminaria com o fim da narrativa. $\mathrm{Na}$ narrativa, por outro lado, "O narrador retira da experiência o que ele conta: sua própria experiência ou a relatada pelos outros" (p. 201). Para ele, "Quem escuta uma história está em companhia do narrador; mesmo quem a lê partilha dessa companhia" (p. 213), o que implica na assertiva de que as narrativas são construídas por muitas vozes e mesmo suas leituras demandam ao menos a presença de duas pessoas - a do leitor e a do narrador. Neste trabalho, portanto, em que contamos sobre os (des)caminhos de uma licencianda, não poderia ser diferente.

Segundo Clandinin e Connelly (2011), a narrativa se configura enquanto um modo de compreender a experiência a partir de histórias vividas e contadas. De acordo com os autores, estudamos a experiência de modo narrativo em função do pensamento narrativo ser uma forma-chave de experiência e um modo-chave de pensar e escrever sobre ela.

Ao trabalharmos na perspectiva de compreender a experiência a partir das histórias vividas e contadas, um ponto de atenção se constrói no que diz respeito ao tratamento das memórias enquanto fatos e, sobretudo nos estudos autobiográficos, os reducionismos que podem compor nossas pesquisas. Ainda consoante aos autores anteriormente citados, os reducionismos acontecem, especialmente, quando os escritores acabam por descrever um evento ou sentimento anterior como se ele fosse exatamente como tal; como se a memória não fosse seletiva ou recontada na continuidade de uma experiência. 


\section{REVISTA ELETRÔNICA \\ DA GRADUAÇÃO/PÓS-GRADUAÇÃO EM EDUCAÇÃO UFG/REJ}

\section{ITINEPARIUS REFLECTIONIS}

ISSN. 1807-9342

Volume 14, N. 2, 2018

Para Cunha e Prado (2017, p.30), a rememoração é uma ação deliberada e intencional. No entanto, as memórias não são plenamente cognoscíveis, pois apresentam duas dimensões: a da lembrança e a do esquecimento. Assim, ao rememorarmos, em companhia das memórias conscientes e intencionais, vêm fios de memórias involuntárias, que de acordo com os autores, são responsáveis por manter a experiência nos esconderijos do esquecimento.

Mas não se pode ter a ilusão do resgate do vivido tal qual ele aconteceu, porque o encontro com passado é mediado por uma vida percorrida no tempo. Há um intervalo de tempo entre o passado e o presente, que age sobre as sensibilidades do sujeito que rememora. Portanto, as memórias, no movimento contínuo da rememoração conseguiriam não perpetuar o vivido, mas reapresentá-lo sempre outro, porque elas não são como blocos monolíticos que contêm o acontecido no passado, mas se (re)configuram a cada encontro de temporalidades (CUNHA E PRADO, 2017, p. 31).

Fazendo uso de suas próprias memórias a pesquisadora foi tensionada a se perguntar: "em que momentos da vida tomei pequenas decisões que podem ter me trazido, dentre outros fatores, para onde estou agora? Quais foram os "sins" e "nãos", o dito e não dito, tanto meus, como de outras pessoas, que ao longo dos anos foram construindo em mim uma identidade docente?"

Seria possível acessar todos esses espaçotempos de modo a encontrar respostas a todas essas perguntas? Acreditamos que considerar essa perspectiva totalizante, colocaria sobre a narrativa todo o peso de uma série de questionamentos com intenção de encontrar respostas concretas, pontuais e assertivas, bem como acreditar que sobre a memória se sobrepõe toda a imparcialidade e precisão, supondo que a ação de rememorar é capaz de operar apenas com experiências "úteis", ou ainda, na certeza de que o que não é lembrado não compõe o processo formativo posto em movimento. Uma leitura realizada a este modo não condiz com os pressupostos da pesquisa narrativa autobiográfica e, ademais, veste o narrador de uma onisciência impossível de se realizar.

Por outro lado, a pesquisa narrativa nos auxilia a construir significados, não em uma perspectiva totalizante, mas de um constante esforço interpretativo de si mesmo, de 


\section{REVISTA ELETRÔNICA \\ DA GRADUAÇÃO/PÓS-GRADUAÇÃO EM EDUCAÇÃO}

UFG/REJ

\section{ITHERAPINIIS \\ REFLCTIONIS}

ISS N. 1807-9342

Volume 14, N. 2, 2018

modo que "as narrações de nós mesmos nos ajudam a construir nosso significado, tanto para cada um, quanto para os outros na sociedade" (RABELO, 2011, pp. 177).

(...) no ato de relatar a reflexividade é ativada, até mesmo porque ao interagir com outra pessoa o sujeito tem a possibilidade de tentar esclarecer os seus motivos e modos de ser. O entendimento de "si mesmo" se realiza somente com um esforço interpretativo. O "si mesmo" é uma narração, pois estamos sempre a contar histórias sobre nós a nós próprios, recuperamos uma memória criando uma nova narrativa (Ibidem, p. 175).

Bruner (1991, pp. 6) nos ensina que as "narrativas têm acontecimentos particulares como sua referência ostensiva. Mas isso é seu veículo, não seu destino”. Na próxima seção do texto apresentamos uma narrativa desse caminho percorrido.

\section{NARRATIVA AUTOBIOGRÁFICA: (re)significando as experiências}

Na minha família, desde pequena, sempre ouvi meus pais dizendo que eu gostava de estudar. Em meu primeiro dia de aula na pré-escola não estava chorosa com medo do abandono da minha mãe como a maior parte das crianças, mas estava ansiosa para começar. Lembro que antes mesmo de aprender a escrever fazia desenhos sem sentido aparente e perguntava para minha mãe se no meio daqueles rabiscos havia alguma letra do alfabeto perdida.

Lembro-me do primeiro dia de aula no qual a professora pediu que escrevêssemos uma página inteira do caderno com as vogais; uma página apenas para $o$ " $a$ ", outra para o "e", " $i$ " e assim por diante. Depois vieram as consoantes e em seguida as páginas da cartilha em que o " $B+A$ ” formam " $B A$ ”. Consigo recordar $d a$ primeira palavra que penso que consegui ler sozinha; era "noiva" e havia um desenho de uma moça com um vestido comprido do lado da palavra escrita na lousa. Hoje, penso que provavelmente essa não tenha sido a primeira palavra que li, pois seria muito mais plausivel que fosse algo como "babá", "bebê" ou "arara”, que são palavras mais simples e presentes nas superfícies textuais e imagéticas das cartilhas de alfabetização. Mas por razões que ainda não compreendo, é essa a memória que em mim permanece. 


\section{REVISTA ELETRÔNICA \\ DA GRADUAÇÃO/PÓS-GRADUAÇÃOO EM EDUCAÇÃO}

UFG/REJ

\section{ITIEEARIIIS \\ REFLECTIONIS}

ISS N. 1807-9342

Volume 14, N. 2, 2018

Durante todo o Ensino Fundamental e Médio sempre me considerei uma aluna mediana e lembro-me até da minha primeira nota vermelha em Ciências na sexta série. Mostrei a nota meio envergonhada para a minha mãe, que disse que tudo bem ter tirado aquele “D+”, mas que isso não se repetisse. Contrariando minha mãe, voltei a repetir a nota algumas vezes no Ensino Médio.

Em alguns momentos me perguntei qual seria a importância e a validade de trazer à tona lembranças tão distantes de um momento em que eu mal pensava sobre o que gostaria de ser quando crescesse. Por que voltar à época da escola, da alfabetização e da primeira nota vermelha?

Larrosa (2006, p. 34), ao relatar um conto de Rousseau, no qual o mesmo traz em seus escritos uma memória de quando era criança em seu livro Confissões, diz que o autor ao se lembrar do episódio relatado faz uma viagem em sua própria biografia, até o fundo de seu eu. Para Larrosa, Rousseau acreditava que a infância e a natureza não estariam apenas no passado, mas também “(...) num lugar escondido no interior de si mesmo, em seu puro centro, no centro mais central dessa série de camadas de cebola que constituem uma personalidade madura" (Ibdem).

Podemos então vir a crer que, ao narrar episódios ocorridos há tanto tempo, lembranças às vezes remotas, mas de alguma forma marcantes - como este que acima foi narrado -, possivelmente estejamos entrando em contato com esse "lugar escondido" em nosso interior, e que é central - depois de atravessar tantas camadas de cebola - na nossa constituição e no processo de construção e reconstrução de nós mesmos.

Como se devêssemos, primeiramente, valorizar essa lembrança por ser algo que nossa mente optou (consciente ou inconscientemente) por guardar e, em segundo lugar, por ao recordar e narrar para os outros e para nós, com base nas crenças do presente e em um diálogo com passado, estamos sempre no ato de procurar por respostas acerca dos traumas e virtudes que constituem o "eu" de agora.

$\mathrm{Na}$ narrativa selecionada para este texto, a alfabetização, as tentativas de escrever algo que fizesse sentido, a boa sensação do primeiro dia de aula, dentre tantas outras lembranças que não apresento aqui, me fazem ponderar que desde o (meu) início o ambiente escolar e as diversas dinâmicas que o envolvem sempre me fizeram bem. Pensar em trabalhar hoje em um ambiente de aprendizagem parece me fazer permanecer em um espaço que, supostamente, sempre foi de conforto. 


\section{REVISTA ELETRÔNICA \\ DA GRADUAÇÃO/PÓS-GRADUAÇÃOO EM EDUCAÇÃO}

UFG/REJ

\section{ITIEEARIIIS \\ REFLECTIONIS}

ISSN. 1807-9342

Volume 14, N. 2, 2018

Ao concluir esse ponto de minha trajetória, no entanto, há a impressão de que eu não poderia estar em outro lugar que não fosse a escola. O que faço, porém, é trazer à tona aquelas lembranças que se fazem coerentes com o momento que vivo e a carreira pela qual optei. Outros caminhos poderiam me levar à outras lembranças que os confirmassem também, assim como outros aspectos de minha personalidade que não estão aqui colocados.

É preciso estar alerta sobre o perigo de tratar as histórias de vida como algo linear, com um enredo no qual tudo desencadeia para um final feliz. É uma história que contamos a nós mesmos e aos outros. Para Nóvoa (2001, p.8), “O que se diz é tão importante como o que fica por dizer. $\mathrm{O}$ que se diz revela uma escolha sem inocências do que se quer falar e do que se quer calar".

Assim, podemos retomar a concepção da autobiografia enquanto um gênero discursivo (BAKHTIN, 2003) no qual conto a minha história - mas a história que quero que seja contada. Não que essa seja mentira e as outras verdades, mas como uma fábula em que as personagens e as situações são escolhidas a partir de um objetivo final. $\mathrm{O}$ propósito da fábula é a moral, na minha narrativa, todavia, é a busca constante pela compreensão do meu próprio "eu", mesmo que este "eu" seja provisório e inacabado.

Segundo Connelly e Clandinin (1988, p. 144), como pesquisadores narrativos, reconhecemos que qualquer fragmento de escrita autobiográfica é "(...) uma reconstrução particular da narrativa de um determinado indivíduo e poderá haver outras reconstruções". Estas novas reconstruções ficariam a cargo de quem ouve ou lê as narrativas, assim como do próprio narrador ao re-narrá-las.

Neves (2010), em seu texto sobre narrativa autobiográfica e formação docente, nos atenta para o uso da escrita pessoal enquanto recurso metodológico, pois se caracterizaria em um esforço individual que buscaria elaborar um conceito distante de nós. Para o passado existe apenas enquanto discurso do presente, pois o presente contém o passado.

Assim, essa construção não se situa no terreno da neutralidade, já que leva em conta a preocupação de como a pessoa se coloca no texto, o que vai demandar importantes decisões envolvendo preocupações sobre o que pode contar e de que forma pode contar essas narrativas. (...) Os comportamentos, os princípios e os valores têm sustentação em nossas histórias de vida e que, 


\section{REVISTA ELETRÔNICA \\ DA GRADUAÇÃO/PÓS-GRADUAÇÃO EM EDUCAÇÃO}

UFG/REJ

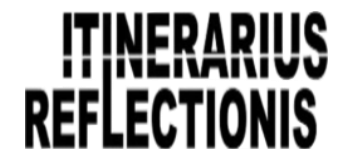

ISSN. 1807-9342

Volume 14, N. 2, 2018

por sua vez, constituem poderosos dispositivos que impulsionam ou influenciam nossas ações, mesmo quando não nos damos conta disso. Desta forma, a experiência é formadora, é possibilitadora de conhecimentos, é exclusiva de cada pessoa (NEVES, 2010, p. 127-128, apud BARBOSA, 2002).

Podemos ainda enunciar que "a narrativa, enquanto prática discursiva no contexto da pesquisa qualitativa em educação favorece o desenvolvimento pessoal e profissional de pesquisadores que tomam sua própria prática, enquanto profissionais da educação, para investigação (RODRIGUES e PRADO, 2015, p. 100).

Dando continuidade ao movimento reflexivo, me reportei ao terceiro ano do Ensino Médio, quando eu e uma amiga decidimos que nossa segunda opção de curso no vestibular deveria ser alguma disciplina que constituísse nossa grade curricular. De modo geral, eu apresentava uma inclinação à área das humanidades, porém, até o presente momento não sei o porquê de naquele dia ter optado por Geografia e não por História, por exemplo. Tenho as minhas desconfianças, mas penso que na época a decisão não aparentava deter tanta importância, visto que não nutria expectativas significativas de passar no vestibular naquele momento.

Durante o ano de cursinho pré-vestibular me apeguei a algumas possibilidades de curso, como Economia e Relações Internacionais, entretanto, de modo geral estava aberta ao que as experiências do cotidiano pudessem me apresentar.

Com o passar das aulas fui me encantando com a organização do cursinho $e$ com os professores que pareciam muito felizes por estarem onde estavam. Cada aula e cada professor me agradavam de um modo diferente e as disciplinas praticamente intoleráveis na escola eram suportáveis e até mesmo divertidas naquele contexto. Enquanto escrevo este texto, pondero que em algum lugar entre o consciente e o inconsciente talvez tenha sido nessa época de minha trajetória que eu tenha vivenciado um contato mais intenso com professores que adoravam ser o que eram: professores. Essa é uma memória muito acentuada até os dias atuais; por um ano frequentei um ambiente de ensino no qual os professores em sua maioria, e na maior parte do tempo, lecionavam sorrindo e pareciam realmente amar o trabalho que estavam desenvolvendo.

Quantas coisas nós nos lembramos e quantas não nos lembramos sem saber a razão? As recordações se alojam em algum lugar de nossas mentes, até que alguém ou 


\section{REVISTA ELETRÔNICA \\ DA GRADUAÇÃO/PÓS-GRADUAÇÃO EM EDUCAÇÃO UFG/REJ}

\section{ITNERRARIIUS REFLECTONIS}

ISSN. 1807-9342

Volume 14, N. 2, 2018

alguma situação nos faça trazê-la à tona. Por que essa memória foi selecionada no meio de tantas outras? Talvez elas existam por uma razão, razão essa que por vezes só entendemos quando pensamos onde estamos e quais foram os caminhos que nos trouxeram até aqui e que ainda provavelmente nos levarão para muitos outros lugares.

Em certa aula durante a graduação, um professor ${ }^{4}$ nos disse que são as pequenas decisões do cotidiano, e não necessariamente as grandes tomadas de tempos em tempos, que determinavam as grandes mudanças em nossas vidas. Presumo, desta forma, que as lembranças que ficam podem ser pistas dessas pequenas decisões que algum dia tomamos ou fragmentos da sensação que as pequenas decisões de outras pessoas deixaram em nós.

A lembrança remete o sujeito a observar-se numa dimensão genealógica, como um processo de recuperação do eu e a memória narrativa, como virada significante, marca um olhar sobre si em diferentes tempos e espaços, os quais se articulam com as lembranças e as possibilidades de narrar experiências. (...) Trabalhar com a memória, seja a memória institucional ou a do sujeito, faz emergir a necessidade de se construir um olhar retrospectivo e prospectivo no tempo e sobre o tempo reconstituído como possibilidade de investigação e de formação de professores. A memória é escrita num tempo, um tempo que permite deslocamento sobre as experiências. Tempo e memória que possibilitam conexões com as lembranças e os esquecimentos de si, dos lugares, das pessoas, da família, da escola e das dimensões existenciais do sujeito narrador (SOUZA, 2007, p. 63-64).

Em minhas andanças pela memória procuro por fragmentos que me levem aos professores que passaram pelo meu caminho e não se foram, na medida em que ainda são parte de mim por terem composto meu percurso formativo. Dois professores de Geografia me vêm em mente.

Assim que percebi, ainda no cursinho, essa admiração que viria a me orientar na escolha do meu curso, acreditava que o que mais me chamava à atenção em ambos era o que eles falavam, eram os diversos conteúdos e temas da Geografia. Com o passar do tempo apreendi, não obstante, que o que eu mais apreciava não era necessariamente “o que”, mas sim “como” eles falavam! Me encantei! Hoje tenho

\footnotetext{
${ }^{4}$ Este episódio se refere à fala do professor Rafael Straforini na disciplina de Tópicos Especiais em Ensino de Geografia, ofertada no primeiro semestre de 2016.
} 


\section{REVISTA ELETRÔNICA \\ DA GRADUAÇÃO/PÓS-GRADUAÇÃO EM EDUCAÇÃO}

UFG/REJ

\section{TTHERAPIIIS REFLECTIONIS}

ISSN. 1807-9342

Volume 14, N. 2, 2018

ainda mais clareza pela visão de mundo proporcionada pela Geografia, pelo seu método de estudo.

Um desses professores também trabalhava como bacharel e, desta forma, eu acreditava que comigo as situações também poderiam se encaminhar desta maneira; era, de fato, algo que eu me visualizava fazendo em meu futuro profissional. Ao ingressar na graduação, portanto, fui em busca das áreas que achava que melhor me direcionariam para o campo do bacharel, começando então a pesquisar sobre mapeamento geomorfológico de áreas litorâneas.

Ao narrar esta parte de meu percurso, desfruto da impressão de que relato a vida de outra pessoa. Um outro sujeito que entrou na universidade com um objetivo definido e uma carreira planejada. Em função desta sensação, a utilização da terceira pessoa para narrar a história parece até mesmo razoável. No entanto, olhando mais de perto, talvez a pessoa que escreve agora não esteja tão distante assim da personagem protagonista da história contada nesses aspectos. O que mudou então? Apesar da identidade provisória e inacabada, como considerei anteriormente, alguns aspectos de nossa personalidade parecem permanecer por mais tempo em nós.

Ao contar nossas histórias, em inúmeros momentos, parece que estamos relatando a vida de outra pessoa e este "contar para o outro" permite que nos recriemos como gostaríamos de sermos visto por quem nos ouve. Pensando acerca do ato de escrever sobre si, Santos (2010, p. 57) coloca que devido à sua dimensão criativa, por vezes os textos autobiográficos carregam uma dimensão de ficcionalidade, de modo que aquele que é autobiografado converte-se em personagem. A autora prossegue afirmando, em sua leitura de Foucault (1992), que a escrita de si está além de

(...) oferecer-se ao olhar do outro para conhecer-se ou situar-se no mundo dos outros, mas é presentificar-se para o outro. (...) Essa presentificação, então, seria menos uma persuasão direta e mais uma influência, algo como um apelo sutil que o signatário lança, pedindo para ser olhado como ele próprio se vê, não como é visto pelos olhos do destinatário. (...) o autor expõe-se, mostra-se, faz aparecer seu próprio rosto perto do outro, ainda que seja seu rosto como gostaria que o outro visse (Ibdem, p.59).

Assim, o sujeito que relata é diferente do que é relatado, uma vez que o primeiro traz em sua prática a autorreflexão, como nos chama a atenção Camargo (2010, p. 18). 


\section{REVISTA ELETRÔNICA \\ DA GRADUAÇÃO/PÓS-GRADUAÇÃOO EM EDUCAÇÃO}

UFG/REJ

\section{THERRPUS \\ REFLECTIONIS}

ISS N. 1807-9342

Volume 14, N. 2, 2018

A autora retoma Catelli (2007) com a ideia de que na autobiografia o informante sofre uma desfiguração. Ou seja, a partir do início da narração - e por consequência do processo autorreflexivo - o sujeito da experiência enquanto escreve não é mais o sujeito da experiência, mas sim uma máscara.

Desta forma, mesmo relatando coisas que de fato sucederam, faz-se relevante a ciência de que foram utilizadas neste texto de memórias selecionadas, não com o intuito de contar uma história falaciosa, mas por acreditarmos que estas rememorações foram consideradas mais significativas ou interessantes para quem nos lê e na construção da própria trajetória de quem fala.

A autobiografia, a partir das narrativas aqui trazidas, nos permite, portanto, refazer caminhos no intento da compreensão da formação docente de uma licencianda, olhando para outro ponto que não o presente, ou seja, olhando para o passado e as experiências vividas com a prerrogativa de encontrar naquilo que é dito e no não dito (deliberadamente) os percursos que que nos trouxeram para esse espaçotempo que nos encontramos atualmente: o de uma licenciatura em Geografia em seus últimos momentos de sua formação inicial.

Dando continuidade ao movimento de pensamentos, comecei a questionar quando a licenciatura passou a ter outro significado para além de uma segunda opção caso a carreira de bacharel apresentasse dificuldades.

Considerei que, desde que optei pela Geografia, a perspectiva de uma carreira docente foi praticamente renegada, e este quadro se intensificava a cada pessoa que me dizia "Geografia? Vai ser professora?" Como se eu procurasse provar para essas pessoas e para mim mesma que eu não seria professora se assim desejasse. No cotidiano, entretanto, nem sempre conseguimos seguir conforme o planejado. Após cerca de dois anos na área da pesquisa escolhida percebi que não era esse o caminho que eu de fato gostaria de trilhar.

Até aquele momento eu sequer estava matriculada na licenciatura e decidi, então, ir à secretaria de graduação e me informar sobre como migrar da modalidade "bacharel" para dupla modalidade, passando a cursar o bacharel e a licenciatura concomitantemente. Apesar desta deliberação, ainda me sentia perdida no sentido de não saber exatamente como lidar a perspectiva de um dia me tornar professora. 


\section{REVISTA ELETRÔNICA \\ DA GRADUAÇÃO/PÓS-GRADUAÇÃO EM EDUCAÇÃO}

UFG/REJ

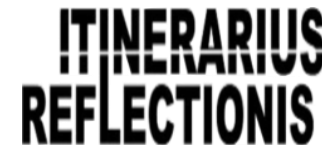

ISS N. 1807-9342

Volume 14, N. 2, 2018

Buscando orientação pedagógica - e por que não, vocacional - procurei o professor Rafael Straforini, professor da área de Ensino de Geografia, coordenador do Pibid - Geografia e do grupo de pesquisa Ateliê de Pesquisas e Práticas em Ensino de Geografia (Apegeo) e, na época, coordenador associado do curso da Geografia Unicamp.

Dialogamos sobre minhas angústias narradas até então e, neste mesmo dia, recebi seu convite para participar do grupo de pesquisa naquele semestre assistindo a uma disciplina sobre ensino de Geografia que ele estava oferecendo na pós-graduação.

Dentro do grupo de pesquisa foi possível me aproximar mais da pesquisa acadêmica, pois mesmo já tendo realizado uma iniciação científica não havia raciocinado sobre meu papel como pesquisadora, sobre a importância de questões metodológicas, sobre a infinidade de temas e vertentes de pesquisa e etc. A participação no grupo propiciou um amadurecimento não apenas no âmbito do acadêmico, mas também no âmbito pessoal.

No segundo semestre do mesmo ano me candidatei a uma das vagas abertas no Pibid-Geografia, iniciando minhas atividades no programa já no mês de agosto. Neste período, também estava cursando as disciplinas pedagógicas do curso. As atividades do Pibid, em concomitância às disciplinas e às leituras e atividades no grupo de pesquisa me colocaram profundamente imersa na licenciatura. A partir de então comecei a visualizar, pela primeira vez, uma possibilidade latente de carreira na área de ensino.

O Pibid-Geografia costumava se organizar guiado pela concepção do professor pesquisador (PEREIRA \& PEREIRA, 2012; KHAOULE, 2012; PIMENTA \& LIMA, 2005/2006) e do cotidiano escolar, ou seja, um professor que exerce a reflexão acerca de seu cotidiano com o intento de mudanças em suas práticas curriculares. Desta forma, ao mesmo tempo que se propunha viver intensamente com o cotidiano das escolas, também se propunha a desenvolver discussões de cunho mais teórico nas reuniões semanais.

Assim, passei a vivenciar o cotidiano escolar, que foi se tornando cada vez mais familiar, mas agora de uma maneira diferente. Se antes a escola era familiar devido ao tempo de escolarização, agora, essa familiaridade era recontextualizada em função das diversas discussões acerca de suas dinâmicas, conflitos, situações e aprendizados. Meu olhar ia aos poucos se modificando, passando do olhar do aluno para o olhar do 


\section{REVISTA ELETRÔNICA \\ DA GRADUAÇÃO/PÓS-GRADUAÇÃO EM EDUCAÇÃO} UFG/REJ

\section{ITwERRMU REFLCTIONIS}

ISSN. 1807-9342

Volume 14, N. 2, 2018

professor de geografia, como se agora eu pudesse entender os dois lados principalmente o do docente, que para mim sempre foi uma incógnita.

Nas primeiras regências ${ }^{5}$ questionava minha competência em lidar com uma turma, principalmente do Ensino Médio, que sempre considerei um desafio maior do que o Ensino Fundamental. Eu já havia lecionado nos primeiros dois anos da graduação em um cursinho popular, mas ainda assim carregava a crença de que "estava" professora e não a de que "era" professora, considerando que aquele momento do meu dia, apesar de me deixar feliz, não era a atividade principal por mim desenvolvida.

Nóvoa (1988, p. 116) nos traz que “(..) ninguém forma ninguém e a formação é inevitavelmente um trabalho de reflexão sobre os percursos da vida". E assim, mais uma vez enquanto escrevo esse texto vou aos poucos identificado momentos da minha vida em que o estar professora foi se tornando uma idealização cada vez distante, ao passo que ser professora foi se tornando central em minha trajetória.

A autorreflexão me leva a crer que neste período a identidade com a licenciatura começou a se dar, também, a partir da negação do bacharel. A identificação com o que eu queria ser se realizava, portanto, com a negação daquilo que já não mais aparentava fazer parte de minha vida.

Agora imersa na licenciatura, comecei a pensar em diversos tópicos que me inquietavam e quais seriam as possibilidades de pesquisa destes temas a partir do que eu vinha descobrindo serem os diferentes caminhos da área de ensino.

Escrever sobre minha trajetória, meus questionamentos, entraves e descobertas ao longo deste tempo permitiu que eu me aproximasse cada vez mais da minha pesquisa de conclusão de curso, me permitiu enxergar o que eu não veria sem esse exercício de autorreflexão. Fazer uso da autobiografia a partir de minhas narrativas possibilitou, desta forma, significar e ressignificar as experiências vividas de modo a perceber o que antes estava escondido em locais recônditos do inconsciente e que se tornaram conscientes pelo exercício de contar a alguém aquilo que vivemos sem que nos déssemos conta.

\footnotetext{
${ }^{5}$ Prática que consistia em dar aula à determinada série depois da elaboração de um plano de aula.
} 


\section{REVISTA ELETRÔNICA \\ DA GRADUAÇÃ O/PÓS-GRADUAÇÃO EM EDUCAÇÃO UFG/REJ}

\section{TTHERAPIIIS REFLECTIONIS}

ISS N. 1807-9342

Volume 14, N. 2, 2018

Como nos traz Larrosa (2006, p. 22), “Talvez (...) não sejamos outra coisa que não um modo particular de contar o que somos. (...) Desse modo, que podemos cada um de nós fazer sem transformar nossa inquietude em uma história? E, para essa transformação, para esse alívio, acaso contamos com outra coisa a não ser os restos desordenados das histórias recebidas [de outras pessoas]?”.

\section{NARRATIVA AUTOBIOGRÁFICA: o encontro com a permanente mudança de quem sou}

Estamos sempre a esperar conclusões; considerações finais. O que concluir quando todos esses processos narrativos nos mostram que nada se encontra terminado?

Acreditamos que nesse momento Larrosa (2006, p. 41) possa falar por nós melhor do que nós mesmos podemos falar:

O homem se faz ao se desfazer: não há mais do que risco, o desconhecido que volta a começar. $\mathrm{O}$ homem se diz ao se desdizer: no gesto de apagar o que acaba de ser dito, para que a página continue em branco. Frente à autoconsciência como repouso, como verdade, como instalação definitiva na certeza de si, prende a atenção ao que inquieta, recorda que a verdade costuma ser uma arma dos poderosos e pensa que a certeza impede a transformação. Perde-te na biblioteca. Exercita-te no escutar. Aprender a ler e a escrever de novo. Conta-te a ti mesmo a sua própria história. E queima-a logo que a tenhas escrito. Não sejas nunca de tal forma que não possas ser também de outra maneira. Recorda-te de seu futuro e caminha até a sua infância. E não pergunte quem é àquele que sabe a resposta, nem mesmo à essa parte de ti mesmo que sabe a resposta, porque a resposta poderia matar a intensidade da pergunta e o que se agita nessa intensidade. Sê tu mesmo a pergunta.

Para Neves (2010) o autorrelato pode ser entendido enquanto o lugar privilegiado entre a vida íntima do sujeito e sua inserção em uma história social e cultural. Se valendo de Carvalho (2003, p.1), afirma que ao trabalharmos com a [auto]biografia, em que o sujeito autor é também o protagonista, estamos sempre em um processo de renegociação e reinvenção identitária. Segundo a autora:

O estudo autobiográfico permite o encontro de múltiplas possibilidades onde o eu pessoal dialoga com o eu social: sou autora e a narradora do texto ao mesmo tempo e, por meio da 


\section{REVISTA ELETRÔNICA \\ DA GRADUAÇÃO/PÓS-GRADUAÇÃO EM EDUCAÇÃO UFG/REJ}

\section{ITNERRARIUS REFLECTIONIS}

ISSN. 1807-9342

Volume 14, N. 2, 2018

autoescuta, posso comunicar ao mundo determinadas coisas que avalio serem importantes. (...) um hibridismo que envolveu lembranças e registros escritos, narrativas que partiam de uma história pessoal, resultando em um exercício que aliou conhecimento, experiência e formação, um olhar para o caminho percorrido, quem sabe uma forma de lidar com perguntas e inquietações (Ibdem, p.124).

Assim, apoiados na teoria acreditamos que no ato de relatar também encontramos espaçotempos para a reflexão sobre os acontecimentos que nos inquietaram no decorrer da pesquisa, das orientações e da escrita do texto final, bem como utilizamos essas reflexões para entender a formação da identidade docente no contexto das atividades do Pibid-Geografia, seja nas reuniões de grupo ou, e principalmente, durante a permanência na escola, na interação com o professorsupervisor e os demais sujeitos escolares. Ao escrever este artigo me reencontrei com as memórias e, uma vez mais, me refiz e me reconectei com a trajetória docente. A minha história, portanto, não tem final assim como este texto, pois estamos sempre em (re) construção. Por ora, posso afirmar que os estudos autobiográficos permitiram que eu me conhecesse um pouco melhor e que, dessa maneira, me ajudaram a dar prosseguimento à minha pesquisa.

$\mathrm{Na}$ escrita narrativa compreendemos a experiência, ainda que esta compreensão se modifique a cada novo relato, a cada novo recontar de nós mesmos.

E isso a que chamamos de autoconsciência ou identidade pessoal, o que parece ter uma forma essencialmente narrativa, não será talvez o sempre provisório e pronto a colapsar que nos damos ao trabalho infinito de distrair, consolar ou acalmar com histórias pessoais, o que nos perturba? É possível que não precisemos senão uma imperiosa necessidade de palavras, pronunciadas ou escritas, ouvidas ou lidas, para cauterizar a ferida (LARROSA, 1995, p. 193).

Dada a contingencialidade da vida, no entanto, não posso dizer o que será daqui para frente, nem se continuarei concluindo coisas que concluo agora, porque como uma dos autores que escreve esse texto já não está mais no presente; já é passado e, como tal, só lhe resta aguardar que a autora do futuro a mantenha em suas memórias e se utilize de suas experiências vividas para continuar significando e ressignificando sua própria existência. 


\section{REFERÊNCIAS}

BAKHTIN, M. Estética da criação verbal. São Paulo. Martins Fontes, 2003.

BARBOSA, J. J. História oral e hermenêutica. Ano 1. N 105. Centro de Hermenêutica do Presente. Porto Velho, 2002.

BRUNER, Jerome. A construção narrativa da realidade. Critical Inquiry, 18(1), pp. $1-21,1991$.

CAMARGO, M. R. R. M. Leitura e escrita como espaços autobiográficos de formação. $1^{a}$ edição. Leituras e escrita como espaços autobiográficos de formação. São Paulo. Editora Unesp, 2010.

CARVALHO, I. C. M. Biografia, identidade e narrativa: elementos para uma análise hermenêutica. Horizontes Antropológicos Vol. 9, No 19 Porto Alegre, 2003.

CATELli, N. En la era de la intimidad. Seguido de: El espacio autobiográfico. Rosário: Beatriz Viterbo Editora, 2007.

COSTA, Adriana Alves Fernandes; EVANGELISTA, Francisco; PRADO, Guilherme do Val Toledo. Narrativas que nos Transformam: o que contam os educandos. São Carlos: Pedro \& João Editores, 2017.

CUNHA, Nara Rúbia de Carvalho; PRADO, Guilherme do Val Toledo. Memórias e Sensibilidade numa produção de conhecimentos históricos-culturais. Revista Memória em Rede. Pelotas, v.10, n.17, Jul./Dez.2017.

EWALD, Felipe Grune. Memória e Narrativa: Walter Benjamin, nostalgia e movência. Revista eletrônica de crítica e teoria de literaturas. Dossiê: oralidade, memória e escrita PPG-LET-UFRGS - Porto Alegre - Vol. 04 N. 02 - jul/dez 2008.

FOUCAULT, M. A escrita de si. 1983. In: O que é um autor? Lisboa: Passagens 1992.

KHAOULE, Anna Maria Kovacs. O estágio supervisionado e suas contribuições na formação do professor de Geografia. In: BENTO, Izabella Peracini \& OLIVEIRA, Karla Annyelly Teixeira de (Orgs.). Formação de professores: pesquisa e prática pedagógica de Geografia. Goiânia: Ed. PUC, 2012, p.57-78.

LARROSA, J. Las paradojas de la autoconciencia. IN: LARROSA, J. et al. Déjame que te cuente - ensayos sobre narrativa y educación. Ed. Laerte. Barcelona, 1995.

Pedagogia profana: danças, piruetas e mascarados. $4^{\mathrm{a}}$ edição. Belo Horizonte: Autêntica, 2006. 


\section{REVISTA ELETRÔNICA \\ DA GRADUAÇÃO/PÓS-GRADUAÇÃO EM EDUCAÇÃO}

UFG/REJ

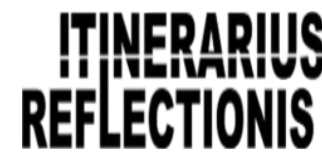

ISS N. 1807-9342

Volume 14, N. 2, 2018

NEVES, J. G. Leitura e escrita como espaços autobiográficos de formação. $1^{\text {a }}$ edição. Cultura escrita e narrativa autobiográfica: implicações na formação docente. São Paulo. Editora Unesp, 2010.

NÓVOA, A. O método (auto)biográfico e a formação. $1^{\text {a }}$ edição. A formaçãa tem de passar por aqui: as histórias de vida no projeto PROSALUS.Lisboa, MS/DRHS/CFAP, 1988.

NÓVOA, A Prefácio. ln: ABRAHÃO, M.H.M.B. (org.). História e Histórias de Vida destacados educadores fazem a história da educação rio-grandense. Porto Alegre: EDIPUCRS, 2001.p. 7-12.

PEREIRA, Regina Coeli Barbosa \& PEREIRA, Rosilene de Oliveira. O estágio supervisionado no contexto da formação de professores. In: CALDERANO, Maria da Assunção (Org.). Estágio Curricular: concepções, reflexões teórico-práticas e proposições. Juiz de Fora: Ed. UFJF, 2012, p.21-34.

PIMENTA, Selma Garrido \& LIMA, Maria Socorro Lucena. Estágio e docência. São Paulo: Cortez, 2011.

PRADO, Guilherme do Val Toledo; SERODIO, Liana Arrais; PROENÇA, Heloísa Helena Dias Martins; RODRIGUES, Nara Caetano. Metodologia Narrativa de Pesquisa em Educação: uma perspectiva bakhtiniana. São Carlos: Pedro \& João Editores, 2015.

RABELO, Amanda Oliveira. A importância da investigação narrativa na educação. Educ. Soc., Campinas, v. 32, n. 114, p. 171-188, jan.-mar. 2011. Disponível em $>$ http://www.cedes. unicamp.br<.

RODRIGUES, Nara Caetano; PRADO, Guilherme do Val Toledo. Investigação Narrativa: construindo novos sentidos na Pesquisa Qualitativa em Educação. Revista Lusófona de Educação, 29, 89-103, 2015.

SANTOS, V. C. C. Leitura e escrita como espaços autobiográficos de formação. $1^{\text {a }}$ edição. Fazeres autobiográficos e cartas pessoas. São Paulo. Editora Unesp, 2010.

SILVA, Ariovaldo Francisco da. A narração como instrumento educativo: as contribuições de Walter Benjamin. VII Coloquio Internacional "Teoría Crítica y Marxismo Occidental", Buenos Aires, 2014.

SOUZA, E. C. Memória e formação de professores. Edição online. (Auto)biografia, histórias de vida e práticas de formação. Salvador: EDUFBA, 2007. Disponível em: <http://books.scielo.org>. 